PLASMA LH, FSH AND TESTOSTERONE RESPONSE TO LH-RH IN 4] BOYS WITH COMPENSATORY TESTICULAR HYPERTROPHY

Laron, Z., Dickerman, Z., Prager-Lewin, R. Keret, R. and Halabe, $E$.

Institute of Pediatric \& Adolescent Endocrinology, Beilinson Hospital, Petach Tikva, and Dept. of Physiology Sackler School of Medicine, Tel Aviv University, Israel.

The plasma LH, FSH and testosterone response to LH-RH was studied in 12 boys with compensatory testicular hypertrophy (CTH) and normal puberty and in a matched control group with normal testicular development. It was found that the boys with CTH had significantly higher basal plasma testosterone levels. At the same time, the basal plasma FSH level was significantly higher in the boys with CTH than it was in the control group, and this high level persisted throughout the LH-RH test. The response of plasma LH to LH-RH was also markedly greater in the CTH group than it was in the control group.

It is concluded that the normal pubertal process seen in the boys with CTH is the result of a hyperfunction or hypersensitivity of the hypothalamic-hypophyseal axis, which may also be responsible for the prepubertal onset of this phenomenon. The hypothalamic compensatory effort is also associated with some abnormality in the control mechanism of the hypophyseal secretion of gonadotrophins.

EFFECTS OF VARIOUS ANDROGENS ADMINISTERED TO

42 PREGNANT GUINEA PIGS ON THEIR FEMALE OFFSPRING. J.J. Van Der Werff Ten Bosch

isconsin Reginal Primate Research Center, ladison, Wisconsin, U.S.A. (now at Erasmus University, RotterWam, Holland).

Gonadectomized adult guinea pigs show different sexual responses to administered sex steroids. After oestradiol benzoate (OB) and progesterone (p) treatment lordosis is shown (upon manual stimulation of the lumbar region, or when mounting attempts are made by a male) by females but not by males.

This response of females is abolished by prenatal administration of the propionate of testosterone (TP) but not of $5 \alpha$-androstan-3 $\alpha, 17 \beta \sim$ diol (ADP) or of $5 \alpha$-dihydrotestosterone (DHTP). Mounting behavior is stimulated by $O B+P$ in both normal and prenatally (TP or ADP or DHTP) treated females but not in males (TP or ADP or ferive groups, while TP stimulated mounting in all categories.

CONCLUSION : None of the prenatal treatments abolishe ness to the various hormones. 43 Ing hypertension In Man? New, M.I., Saenger, P.H. Levine, L.S. Peterson, R.E., Cornell

Univ.Med.Col., Dept. Ped. \& Med., New York, N.Y.

The hypothesis that a steroid can produce hypertenion in man was tested in an $18 \mathrm{yr}$. old male with dexamethasone-suppressible hypertension. Reinvestigation after 6 yrs. of little or no treatment demonstrated that the hypertension and mild hyperaldosteronism were promptiy decreased by a small when aldosterone secre During dexamathe normal and he was tion was son constant infusion normotensive, steroids were given hypertension of the in an attempt to reproduce the hypertension of the dexamethasone-free state. Neither 5 days of aldosterone (A) nor 18-hydroxy desoxycorticosterone (18-oH Doc) $1 \mathrm{mg} / \mathrm{day}$ nor However, $\mathrm{Na}$ retention and $A$ and DOC infusion. The days during infusion of ACTH or oral metyrapone. The hypertensive effect of the latter was eliminated by addition of aminogluthethimide treatment. These studies suggest that an ACTH dependent sterof other the hypertension in this patient.

$$
\text { in this patient. }
$$

STUDIES ON THE RELATIVE SENSITIVITY FOR AN-

44. DROGEN FEEDRACK INHIBITION IN RATS DURINO SEXUAL MATURATION. K. Rager, M.Eichner, W. Willmann, D. Gupta. Univ. Children's Hospital, Tübingen, W-Germany.

This set of experiments was designed to see : (1) the relative sensitivity of a number of androgens on the feedback inhibition of gonadotropins, (2) if there is any alteration in the magnitude of feedback inhibition with sexual maturation. Testosterone, dihydrotestosterone, $3 k$-androstanediol and androstenedione were given in one injection s.c. as $250 \mu \mathrm{g} / 100 \mathrm{~g}$ body weight at the ages $16,23,26,35,56,65$ and 90 days. 24 hrs later at the ages $16,23,26,35,56,65$ and 90 days. 24 hrs late LH and FSH were measured. The results suggest, that (1) The 2 adrenal androgens DHA and $\Delta 4$ have no suppressive T DHT $3 x$-Adiol suppressed LH secretion the order being 3K-Adiol, DHT, $T$ at the period of 26-35 days where maxi3K-Adiol, mum suppression was observed, ted $F S H$ in all ages in male rats, whereas $3 \alpha$-Adiol was ineffective, (4) The inhibition of the gonadotropins was found to be age dependent with the same dose administered, (5) The same dose of androgens suppressed maximally at days 26 and 35. In younger animals the suppression was not as marked but significantly lower than seen in the older age groups, (6) For FSH the situation is not as clear as that for Lil, but still comparable. $T$ and DHT had bigger inhibition in premature animals than in adults.

\section{EFFECTS OF HANUTRITION} G.R.Beaton, D. Becker ${ }^{\circ}$ and B.I.Pimstone ${ }^{\circ}$

tDepartment of Physiolozy, University of the Witwatersrand \& o Department of liedicine, University of Cape Town, South Africa.

The effects of intravenous infusion of $2 \mathrm{mg} \mathrm{HGH}$ on serum somatomedin (SM) and free fatty acids (FFA) in 5 children with severe kwashiorkor on admission to hospital and af'ter rehabilitation have been studied.

SM, measured by the porcine cartilage technique of Van den Brande, was low on admission and rose after recovery 15 to $3, \bar{j}$ days later. HGH infusion hal no significant effect on SM 3 and 5 hours after infusion on either occasion in any of the subjects.

Fasting serum FFA on admission ranged from 573 to 1245 microeq/ 1 with a mean rise of $16 \% 3$ hours after infusion. After rehabilitation fasting levels fell, ranging from 282 to 864 microeq $/ 1$, with a mean rise of $102 \% 3$ hours after infusion.

\section{6 (GH), TSH AND CORTISOL IN CHILDREN.}

Sergio Bernasconi, Toni Torresani and Ruth Illig. Univ. Zürich, Sch.Med., Dept. Ped., Kinderspital, Zürich, Switzerland

The effect of $\alpha-M S H$ was studied in 19 prepubertal children (mean age $6.85 \mathrm{yrs}$ ) with small stature. The tests have been performed in order to rule out GH deficiency.

a-MSH was injected intravenously ( $3 \mathrm{mg}$ during 1-2 $\mathrm{min}$.). Blood samples were taken at $0,15,30,45$ and $60 \mathrm{~min}$. In addition, all children had arginine and insulin tolerance tests. GH and TSH were determined by RIA, cortisol by protein binding assay.

Results : a-MSH was well tolerated, no untoward or stress reactions could be observed. A normal $\mathrm{GH}$ response to $a-M S H$ was seen only in 2 out of 8 children with constitutional small stature and otherwise normal $\mathrm{GH}$ secretion. 3 of 11 children suffering from hypopituitarism with documented $\mathrm{GH}$ and other hormonal deficiencies, unexpectedly, showed a small but significant rise of $\mathrm{GH}$ after a-MSH; all 3 had craniopharyngeoma.

a-MSH led to a clear cut increase of cortisol in all but 3 patients with secondary adrenal insufficiency requiring steroid replacement therapy. In each single child, the rise of cortisol after $\alpha-M S H$ and after insulin was of equal size suggesting a common mechanism of action. However, hypogly cemia and stress, as seen in the insulin tolerance test, has not been observed after $a-M S H$.

There was no effect of $a-M S H$ on plasma TSH. 